\title{
Remifentanil dose for laryngeal mask airway insertion with a single standard dose of propofol during emergency airway management in elderly patients
}

\author{
Junghee Ryu ${ }^{1}$, Ah Young $\mathrm{Oh}^{1}$, Ji-Seok Baek ${ }^{1}$, Jin-Hee Kim ${ }^{1}$, Sang-Heon Park ${ }^{1}$, and Jae-Mun Noh ${ }^{2}$ \\ Department of Anesthesiology and Pain Medicine, ${ }^{1}$ Seoul National University Bundang Hosptial, Seongnam, ${ }^{2}$ Seoul National \\ University Hosptial, Seoul, Korea
}

Background: This study determined the dose of remifentanil to use during insertion of a Classic ${ }^{\mathrm{TM}}$ laryngeal mask airway (LMA, The Laryngeal Mask Co., Nicosia, Cyprus) in elderly patients during emergency airway management when combined with a single dose of propofol.

Methods: Patients aged 65-80 years were enrolled. Anesthesia was induced with propofol $1 \mathrm{mg} / \mathrm{kg}$, and then a blinded dose of remifentanil was infused over $30 \mathrm{~s}$ after confirming the patient's loss of consciousness. The dose of remifentanil was determined using Dixon's up-and-down method, starting at $0.5 \mu \mathrm{g} / \mathrm{kg}$ (a step size of $0.1 \mu \mathrm{g} / \mathrm{kg}$ ). Insertion of the LMA was attempted $60 \mathrm{~s}$ after loss of consciousness.

Results: In total, 23 patients were recruited and the mean age \pm standard deviation was $72 \pm 3$ years. The effective dose for successful LMA insertion in $50 \%$ of the patients $\left(\mathrm{ED}_{50}\right)$ was $0.20 \pm 0.05 \mu \mathrm{g} / \mathrm{kg}$. No patient needed more than $0.3 \mu \mathrm{g} / \mathrm{kg}$. Conclusions: Remifentanil $0.20 \pm 0.05 \mu \mathrm{g} / \mathrm{kg}$ with propofol $1 \mathrm{mg} / \mathrm{kg}$ resulted in excellent LMA insertion in $50 \%$ of elderly patients without significant hemodynamic changes during emergency airway management. (Korean J Anesthesiol 2014; 66: 278-282)

Key Words: Aged, Laryngeal mask airway, Remifentanil.

\section{Introduction}

The use of the laryngeal mask airway (LMA) has increased in anesthesia. In addition to the induction of anesthesia, LMA insertion is also useful during emergency airway management, such as with a difficult airway or in an emergency [1,2]. How- ever, an adequate depth of anesthesia is needed for successful insertion of the LMA to prevent untoward events such as coughing and laryngospasm [3]. Recent studies have shown that remifentanil, in combination with propofol, provides adequate conditions for LMA insertion in adults [3-6].

The number of elderly patients is increasing with advances

Received: June 24, 2013. Revised: 1st, July 26, 2013; 2nd, September 17, 2013. Accepted: September 23, 2013.

Corresponding author: Ah Young Oh, M.D., Department of Anesthesiology and Pain Medicine, Seoul National University Bundang Hospital, 300, Gumi-dong, Bundang-gu, Seongnam 463-707, Korea. Tel: 82-31-787-7506, Fax: 82-31-787-4063, E-mail: oay1@snubh.org

(c) This is an open-access article distributed under the terms of the Creative Commons Attribution Non-Commercial License (http:// creativecommons.org/licenses/by-nc/3.0/), which permits unrestricted non-commercial use, distribution, and reproduction in any medium, provided the original work is properly cited. 
in medicine and public health care [7]. These patients often have comorbidities and respond differently to anesthetic agents due to altered pharmacokinetics and pharmacodynamics [7]. Therefore, it is important to understand the differences in sensitivity to many drugs in elderly patients and to use titrated doses to minimize untoward cardiovascular events [8]. However, we could find no article on the remifentanil dose during LMA insertion in elderly patients during emergency airway management. Therefore, this study was performed to determine the dose of remifentanil needed to obtain excellent Classic ${ }^{\mathrm{TM}}$ LMA insertion in elderly patients when used in combination with a single induction dose of propofol during emergency airway management.

\section{Materials and Methods}

The study protocol was approved by the Institutional Review Board and registered with the Clinical Research Information Service (ref: KCT0000088). After obtaining written informed consent, ASA physical status I or II patients aged 65 to 80 years, who were scheduled for elective surgery under general anesthesia and eligible for LMA were enrolled. Patients with uncontrolled hypertension, a history of reactive airway disease or body mass index (BMI) $\geq 30 \mathrm{~kg} / \mathrm{m}^{2}$, or who had a suspected difficult airway (Mallampati class III, IV) were excluded.

The patients were premedicated with intravenous (IV) glycopyrrolate $0.2 \mathrm{mg}$ and midazolam $0.02 \mathrm{mg} / \mathrm{kg}$ in the reception area before inducing anesthesia. In the operating room, all patients were monitored with an electrocardiogram, pulse oximetry, and noninvasive blood pressure. After preoxygenation for 3 min, anesthesia was induced with IV propofol (Anepol ${ }^{\circledR}$, Hana Pharmaceutical, Seoul, Korea) $1 \mathrm{mg} / \mathrm{kg}$. Then, a predetermined dose of remifentanil (Ultiva ${ }^{\circledR}$, GlaxoSmithKline Korea, Seoul, Korea) was injected over $30 \mathrm{~s}$ after confirming the patient's loss of consciousness (loss of eyelash reflex). The dose of remifentanil was determined using Dixon's up-and-down method [9], starting from $0.5 \mu \mathrm{g} / \mathrm{kg}$. If the previous patient's LMA insertion was excellent, the next patient's remifentanil was decreased by $0.1 \mu \mathrm{g} / \mathrm{kg}$. If the previous patient's LMA insertion was good or poor, the next patient's remifentanil was increased by $0.1 \mu \mathrm{g} / \mathrm{kg}$. Assisted mask ventilation with $100 \% \mathrm{O}_{2}$ was given as needed. Classic $^{\text {TM }}$ LMA (The Laryngeal Mask Co., Nicosia, Cyprus) in- sertion was attempted $60 \mathrm{~s}$ after remifentanil infusion (Fig. 1). The LMA was inserted by a single experienced anesthesiologist who was blinded to the dose of remifentanil used using a $90^{\circ}$ rotation technique [10]. Patients with poor condition for LMA insertion were assisted mask ventilation with sevoflurane and $100 \% \mathrm{O}_{2}$ and then administered $0.6 \mathrm{mg} / \mathrm{kg}$ of rocuroniums for endotracheal intubation.

The LMA insertion was graded on a three-point scale: grade 1 , excellent, no response to LMA insertion; grade 2, good, slight gagging or swallowing with LMA insertion; grade 3, poor, unable to open mouth, biting or gross movement upon LMA insertion [6]. Only excellent was regarded as a success. The mean arterial pressure (MAP) and heart rate (HR) were recorded on arrival in the operating room, before the start of anesthesia induction (Base), after injecting the propofol (Propofol), just before inserting the LMA (PreLMA), and 1, 2, and 3 min after inserting the LMA (LMA1, LMA2, and LMA3, respectively). Bradycardia (HR $<60 / \mathrm{min}$ or a decrease $>15 / \mathrm{min}$ from baseline) was treated with atropine $0.5 \mathrm{mg}$, and hypotension (systolic blood pressure $[\mathrm{SBP}]<90 \mathrm{mmHg}$ or a decrease in SBP $>20 \%$ from baseline) was treated with ephedrine $5 \mathrm{mg}$ intravenously. Patients were also asked about sore throat and any recall of intraoperative events just before discharge from the postanesthesia care unit (PACU).

The patient data are presented as mean \pm SD. Dixon's up-anddown method needs at least six success-failure pairs for statistical analysis [9]. $\mathrm{ED}_{50}$ was defined as the mean of the cross-over doses. Differences in MAP and HR over time for each dose of remifentanil were analyzed with repeated measures analysis of variance (ANOVA) with the Bonferroni multiple-comparison test. A P value less than 0.05 was considered significant.

Table 1. Patient Characteristics

$\begin{array}{lc}\text { Gender }(\mathrm{M} / \mathrm{F}) & 15 / 8 \\ \text { ASA physical status (I/II) } & 5 / 18 \\ \text { Age }(\mathrm{yr}) & 72 \pm 3 \\ \text { Weight }(\mathrm{kg}) & 69 \pm 7 \\ \text { Height }(\mathrm{cm}) & 166 \pm 5 \\ \text { Body mass index }\left(\mathrm{kg} / \mathrm{m}^{2}\right) & 25 \pm 2\end{array}$

Values are mean \pm SD or numbers. ASA: American Society of Anesthesiologists.

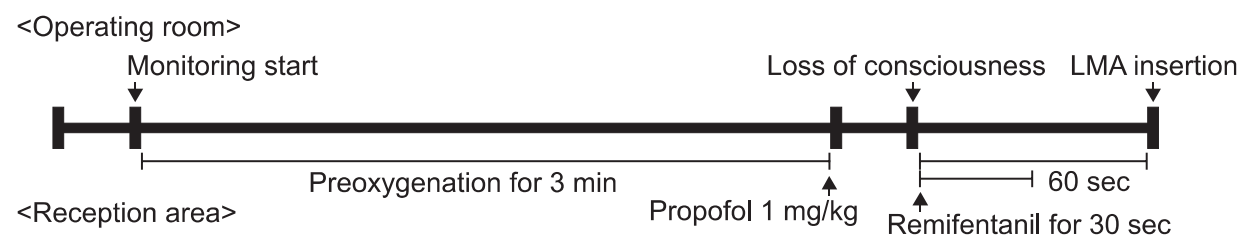

Glycopyrrolare $0.2 \mathrm{mg}$

Midazolam $0.2 \mathrm{mg} / \mathrm{kg}$
Fig. 1. Time line of medications during induction of anesthesia. LMA: laryngeal mask airway. 


\section{Results}

Twenty-eight patients were assessed for eligibility. Five patients were excluded: two refused to participate, two were obese $\left(\mathrm{BMI} \geq 30 \mathrm{~kg} / \mathrm{m}^{2}\right)$, and one had a history of asthma. The 23 enrolled patients finished the study and were analyzed to obtain seven pairs of success-failure combinations. The patient characteristics are shown in Table 1.

The plots of the dose of remifentanil associated with success or failure of LMA insertion for each consecutive patient are shown in Fig. 1. The $\mathrm{ED}_{50}$ of remifentanil for excellent LMA insertion (grade 1) was $0.20 \pm 0.05 \mu \mathrm{g} / \mathrm{kg}$ with Dixon's up-and-down method. As a result, patients received $0.1(n=5), 0.2(n=10), 0.3$

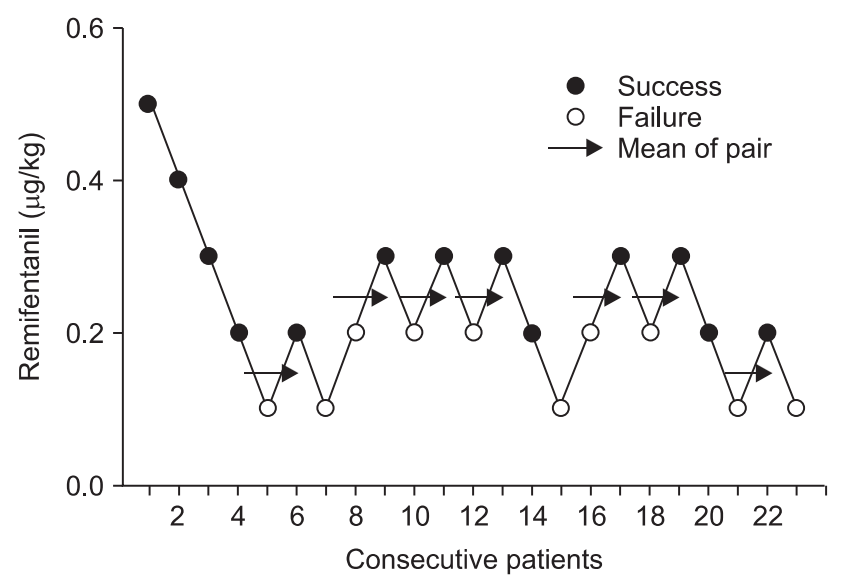

Fig. 2. The responses of 23 consecutive patients to LMA insertion. Arrows indicate the midpoint of the dose of remifentanil of all independent pairs of patients involving crossover from a failure to a success. The dose of remifentanil needed for excellent condition of LMA insertion in 50\% of patients $\left(\mathrm{ED}_{50}\right)$ was $0.2 \pm 0.05 \mu \mathrm{g} / \mathrm{kg}$ with a Dixon's up-and-down method. $(\mathrm{n}=6), 0.4(\mathrm{n}=1)$, or $0.5(\mathrm{n}=1) \mu \mathrm{g} / \mathrm{kg}$ of remifentanil (Fig. 2$)$.

MAPs of success group were lower than those of fail group just before inserting the LMA (PreLMA), 1, and 3 min after inserting the LMA (LMA1 and 3) whereas there was no significant difference in HR over time between success and fail group (Fig. 3).

The LMA insertion conditions for each dose of remifentanil are presented in Table 2. All patients in the success group showed excellent condition. In the fail group, 70\% (7/10) showed

Table 2. Conditions of LMA Insertion in Patients

\begin{tabular}{lcc}
\multicolumn{1}{c}{ Grade } & $\begin{array}{c}\text { Success group } \\
(\mathrm{n}=13)\end{array}$ & $\begin{array}{c}\text { Fail group } \\
(\mathrm{n}=10)\end{array}$ \\
\hline $\begin{array}{l}\text { 1: Excellent } \\
\text { No response to LMA insertion }\end{array}$ & $13(100)$ & 0 \\
2: Good & 0 & $7(70)$ \\
$\begin{array}{l}\text { Slight gagging or swallowing } \\
\text { with insertion of LMA }\end{array}$ & $3(30)$ \\
3: Poor & 0 & \\
$\quad \begin{array}{l}\text { Unable to open mouth, } \\
\text { biting or the gross movement }\end{array}$ & & \\
\hline
\end{tabular}

Values are presented as numbers (\%).

Table 3. Adverse Events During Insertion of a LMA

\begin{tabular}{lccc}
\hline & $\begin{array}{c}\text { Success group } \\
(\mathrm{n}=13)\end{array}$ & $\begin{array}{c}\text { Fail group } \\
(\mathrm{n}=10)\end{array}$ & P value \\
\hline Sore throat & $0(0)$ & $4(40)$ & 0.024 \\
Recall & $0(0)$ & $0(0)$ & $\mathrm{NS}$ \\
Hypotension & $1(8)$ & $1(10)$ & $>0.99$ \\
Bradycardia & $0(0)$ & $0(0)$ & NS \\
\hline
\end{tabular}

Values are expressed as numbers (\%).
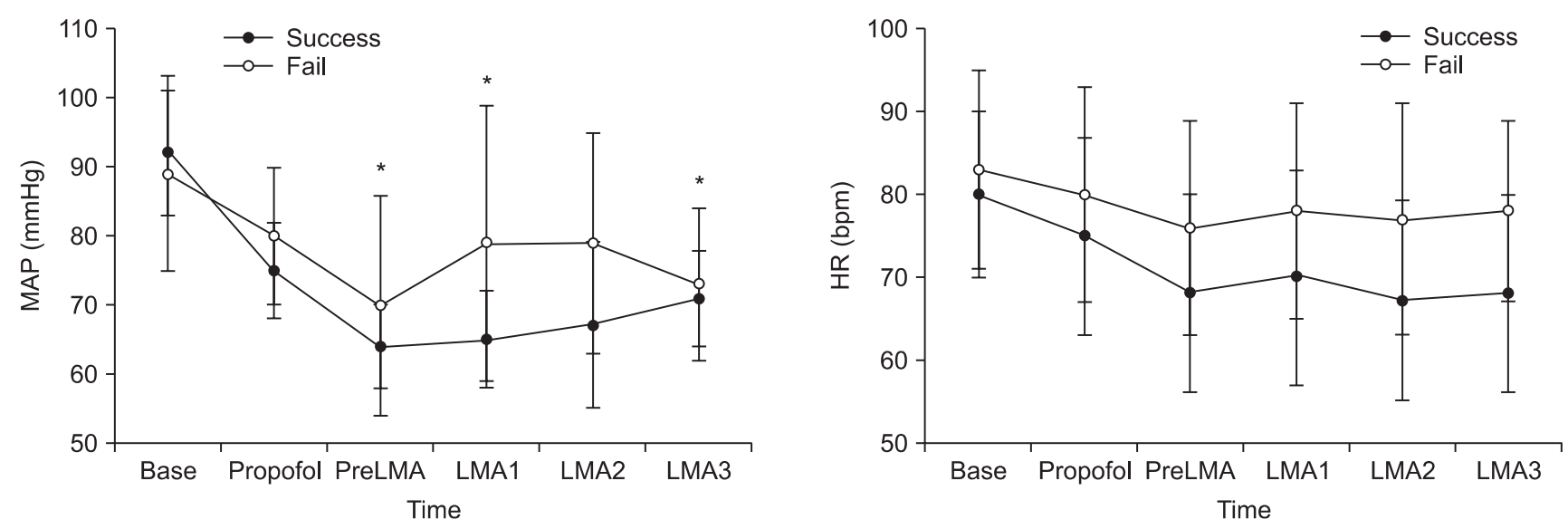

Fig. 3. Hemodynamic changes during the study period. Mean arterial pressures (MAPs) were lower in success group at immediately before LMA insertion and 2 and 3 min after There was no significant difference in the MAP and HR over time among patients with each dose of remifentanil. Base: before the start of induction of anesthesia, Propofol: $30 \mathrm{~s}$ after propofol injection, PreLMA: immediately before LMA insertion, LMA1, LMA2, LMA3: $1 \mathrm{~min}, 2 \mathrm{~min}, 3 \mathrm{~min}$ after LMA insertion. ${ }^{*} \mathrm{P}<0.05$ compared with fail group. 
good condition and 30\% (3/10) showed poor condition (Table 2).

During insertion of LMA, 2 patients (each patient in success and fail group) needed ephedrine for hypotension, and no patient showed bradycardia. Before discharge from the PACU, 4 of the fail group (40\%) complained sore throats. No patient recalled any intraoperative events (Table 3 ).

\section{Discussion}

Using Dixon's up-and-down method, we found that the dose needed for excellent LMA insertion in $50 \%$ of elderly patients $\left(\mathrm{ED}_{50}\right)$ was $0.20 \pm 0.05 \mu \mathrm{g} / \mathrm{kg}$ during emergency airway management when combined with $1 \mathrm{mg} / \mathrm{kg}$ of propofol.

The LMA should be inserted after adequate anesthesia [3]. Short-acting narcotics such as alfentanil improved the results of LMA insertion and reduced the incidence of laryngospasm $[11,12]$. Remifentanil is unique in that it has an ultra-short duration of action due to rapid degradation by tissue and blood esterases [13]. Additionally, remifentanil provides immediate adequate conditions for airway management without delaying recovery, which is beneficial for emergency airway management.

This study was designed to investigate the proper dose of remifentanil during LMA insertion for emergency airway management of elderly patients. We chose an initial remifentanil dose of $0.5 \mu \mathrm{g} / \mathrm{kg}$. Various remifentanil doses for successful LMA insertion in adults have been reported [3-6]. Lee et al. [6] suggested that remifentanil $0.25 \mu \mathrm{g} / \mathrm{kg}$ with propofol $2.5 \mathrm{mg} / \mathrm{kg}$ was adequate for LMA insertion in adults. Another study estimated the $\mathrm{ED}_{95}$ of remifentanil combined with propofol $2.5 \mathrm{mg} / \mathrm{kg}$ to be $1.2-1.4 \mu \mathrm{g} / \mathrm{kg}$ [3]. In general, elderly patients are more sensitive to anesthetics and have higher serum concentrations for a given dose because of changes in pharmacodynamics and pharmacokinetics [7]. The reduced clearance and volume of distribution in elderly patients results in high peak concentrations after remifentanil bolus administration. Usually, half the bolus dose of remifentanil is recommended in elderly patients [7,13], and therefore an initial remifentanil dose of $0.5 \mu \mathrm{g} / \mathrm{kg}$ was selected.

The result of the current study with Dixon's up-and-down method suggested that the dose of remifentanil $0.2-0.3 \mu \mathrm{g} / \mathrm{kg}$ with $1 \mathrm{mg} / \mathrm{kg}$ of propofol provided excellent LMA insertion in elderly patients. The dose of remifentanil from this result was somewhat less than the expected value considering that less propofol $(1 \mathrm{mg} / \mathrm{kg})$ was used compared with those with adults $(2.5$ $\mathrm{mg} / \mathrm{kg}$ ) of the previous investigations $[4,6]$.

We hoped to determine the adequate dose of remifentanil for LMA insertion in emergency airway management, such as with an expected difficult airway or in urgent situations. Patients usually lost their consciousness within $30 \mathrm{~s}$ and the time interval between administration of propofol and insertion of LMA was less than $90 \mathrm{~s}$. That is why we tried inserting the LMA at $60 \mathrm{~s}$ after the loss of consciousness and infusion of remifentanil, which is the maximum time interval without inducing arterial desaturation [14]. However, the time to the peak effect of remifentanil is about $1.6 \mathrm{~min}$ [13] and, moreover, elderly patients have slower onsets, with times to the peak effect of 2-3 min [8]. If we had waited longer for time to the peak effect before LMA insertion, the results would have been different, tending to greater success. That is, our data were acquired for an emergency airway management situation, but they can be used in stable situations without decreasing the success rate.

Remifentanil was administered after confirming the loss of consciousness with propofol, and no patient needed additional propofol. Propofol is an anesthetic commonly used for LMA insertion [3-6]. Elderly patients require about 50\% less propofol than do adult patients to maintain the same drug effect because of decreased clearance and increased intrinsic sensitivity [8]. Therefore, we used $1 \mathrm{mg} / \mathrm{kg}$ of propofol as the induction dose, which is much lower than the recommended adult induction dose of $2.5 \mathrm{mg} / \mathrm{kg}[3,6,15]$. However, the concentration of propofol seems to be somewhat low in this study and there is a possibility that the need of remifentanil could be influenced by the concentration of propofol.

We regarded only excellent insertion as success, in line with previous studies $[3,5,6]$, because subjectivity arises when distinguishing good and poor results. However, a good insertion, i.e., a slight response on inserting the LMA, may also be acceptable clinically. The insertion technique might have affected our success rate. Instead of the conventional insertion technique, the $90^{\circ}$ rotation technique, which is reported to have a greater success rate at the first attempt and to result in less sore throat and less laryngeal injury, was used for LMA insertion [10]. Additionally, premedication with midazolam may influence the dose of remifentanil and insertion results. One patient with $0.1 \mu \mathrm{g} / \mathrm{kg}$ and 2 patients with $0.2 \mu \mathrm{g} / \mathrm{kg}$ showed poor conditions for LMA insertion and endotracheal intubation was done after assisted ventilation with sevoflurane and administration of muscle relaxant.

Remifentanil can attenuate the hemodynamic response during the induction of anesthesia, but it may result in hypotension and bradycardia [16]. Despite this concern, the majority of our elderly patients maintained cardiovascular stability. This is another important consideration in compromised elderly patients, i.e., avoiding hemodynamic instability during the induction of anesthesia. Two of the 23 patients (each patient in success and fail group) developed hypotension, which was treated with ephedrine. Bradycardia, a potential complication of remifentanil, did not occur. A possible explanation is the relatively small doses of remifentanil and premedication with glycopyrrolate.

The weakness of this study is that only the $\mathrm{ED}_{50}$ (not the $\mathrm{ED}_{95}$ ) was determined with only 23 patients. As this study used the up-and-down method, the $\mathrm{ED}_{50}$ could be obtained with as 
few as one-fifth the numbers (only 23 patients) of patients as the traditional design with a preset number of patients at each level [9]. This means that we could minimize the number of patients given insufficient treatment. However, $\mathrm{ED}_{95}$ could not be obtained with probit analysis because adequate number of remifentanil concentration was not used in this study. We assumed that the $\mathrm{ED}_{95}$ of remifentanil is $<0.3 \mu \mathrm{g} / \mathrm{kg}$ because all six patients given $0.3 \mu \mathrm{g} / \mathrm{kg}$ remifentanil had excellent LMA insertion but the number of patients seems to be inadequate to make a conclusion.
In conclusion, we suggest that the $\mathrm{ED}_{50}$ of remifentanil in combination with propofol $1 \mathrm{mg} / \mathrm{kg}$ for elderly patients during emergency airway management was around $0.2 \mu \mathrm{g} / \mathrm{kg}$, which is lower than that of adult patients. Therefore it seems that $\mathrm{ED}_{95}$ of remifentanil in elderly patients during LMA insertion may also be considered to be lower than that of previous investigations for adult patients. Further study is needed for the $\mathrm{ED}_{95}$ of remifentanil in elderly patients during emergency airway management with LMA.

\section{References}

1. Jolliffe L, Jackson I. Airway management in the outpatient setting: new devices and techniques. Curr Opin Anaesthesiol 2008; $21: 719-22$.

2. Agrò FE, Cataldo R, Mattei A. New devices and techniques for airway management. Minerva Anestesiol 2009; 75: 141-9.

3. Bouvet L, Da-Col X, Rimmelé T, Allaouchiche B, Chassard D, Boselli E. Optimal remifentanil dose for laryngeal mask airway insertion when co-administered with a single standard dose of propofol. Can J Anaesth 2010; 57: 222-9.

4. Grewal K, Samsoon G. Facilitation of laryngeal mask airway insertion: effects of remifentanil administered before induction with targetcontrolled propofol infusion. Anaesthesia 2001; 56: 897-901.

5. Kim MK, Lee JW, Jang DJ, Shin OY, Nam SB. Effect-site concentration of remifentanil for laryngeal mask airway insertion during targetcontrolled infusion of propofol. Anaesthesia 2009; 64: 136-40.

6. Lee MP, Kua JS, Chiu WK. The use of remifentanil to facilitate the insertion of the laryngeal mask airway. Anesth Analg 2001; 93: 359-62.

7. Rivera R, Antognini JF. Perioperative drug therapy in elderly patients. Anesthesiology 2009; 110: 1176-81.

8. Shafer SL. The pharmacology of anesthetic drugs in elderly patients. Anesthesiol Clin North America 2000; 18: 1-29.

9. Dixon WJ. Staircase bioassay: the up-and-down method. Neurosci Biobehav Rev 1991; 15: 47-50.

10. Hwang JW, Park HP, Lim YJ, Do SH, Lee SC, Jeon YT. Comparison of two insertion techniques of ProSeal laryngeal mask airway: standard versus 90-degree rotation. Anesthesiology 2009; 110: 905-7.

11. Hui JK, Critchley LA, Karmakar MK, Lam PK. Co-administration of alfentanil-propofol improves laryngeal mask airway insertion compared to fentanyl-propofol. Can J Anaesth 2002; 49: 508-12.

12. Yu AL, Critchley LA, Lee A, Gin T. Alfentanil dosage when inserting the classic laryngeal mask airway. Anesthesiology 2006; 105: 684-8.

13. Minto CF, Schnider TW, Shafer SL. Pharmacokinetics and pharmacodynamics of remifentanil. II. Model application. Anesthesiology 1997; 86: 24-33.

14. Weingart SD, Levitan RM. Preoxygenation and prevention of desaturation during emergency airway management. Ann Emerg Med 2012; 59: 165-75.

15. Bouvet L, Stoian A, Rimmelé T, Allaouchiche B, Chassard D, Boselli E. Optimal remifentanil dosage for providing excellent intubating conditions when co-administered with a single standard dose of propofol. Anaesthesia 2009; 64: 719-26.

16. Hall AP, Thompson JP, Leslie NA, Fox AJ, Kumar N, Rowbotham DJ. Comparison of different doses of remifentanil on the cardiovascular response to laryngoscopy and tracheal intubation. Br J Anaesth 2000; 84: 100-2. 